Protestantismo em Revista é licenciada sob uma Licença Creative Commons.

http://dx.doi.org/10.22351/nepp.v43i2.3009

\title{
Educação confessional: o perfil do aluno de Escolas Adventistas
}

\author{
Confessional education: the student profile of Adventist Schools
}

Patrick Vieira Ferreira*

\begin{abstract}
Resumo
Esta pesquisa tem por finalidade conhecer e analisar o perfil dos alunos da educação confessional que estudam em escolas da Rede Adventista de Educação. A metodologia utilizada para conhecer esse perfil foi do tipo descritivo-exploratório, sendo realizada com uso de questionários aplicados a alunos do ensino básico (Fundamental e Médio) de seis escolas confessionais pertencentes à Rede Adventista de Educação localizadas na Zona Leste e Norte da cidade de São Paulo, divulgados por meio eletrônico pela mantenedora das escolas investigadas. Atualmente, o crescimento da procura pelas instituições de ensino confessional é admirável. Essa procura trouxe como principal destaque a mudança do perfil discente que frequentava as escolas adventistas. As respostas de 1.787 alunos indicaram serem de juvenis e adolescentes, que professavam pertencer a diversas religiões, mas que demonstraram ter interesses na religiosidade/espiritualidade em sala de aula.
\end{abstract}

\section{Palavras-chave}

Educação adventista. Educação confessional. Perfil de aluno.

\begin{abstract}
This research aims to know and analyze the profile of confessional education students who study in schools of the Adventist Education Network. The methodology used to know this profile was descriptiveexploratory, being carried out with the use of questionnaires applied to elementary and middle school students from six confessional schools belonging to the Adventist Education Network located in the East and North Zone of the city of São Paulo, published by electronic means by the maintainer of the schools investigated. Currently, the growth of demand for denominational institutions is admirable. This demand brought the main focus of the change in the student profile that Adventist schools attended. The responses of 1,787 students indicated that they were from youths and adolescents, who professed to belong to different religions, but
\end{abstract}

[Texto recebido em maio de 2017 e aceito em janeiro de 2018, com base na avaliação cega por pares realizada por pareceristas ad hoc]

* Mestre em Educação (UMESP). Especialista em Gestão Educacional e Capelania Escolar. Licenciado em Pedagogia (FAENE). Graduado em Teologia (SALAT). Coaching Profissional certificado pela Sociedade Latino-Americana de Coaching. Integrante do corpo administrativo em escolas da Rede de Educação Adventista. E-mail: patrick.ferreira@ucb.org.br 
who showed that they had interests in religiousness / spirituality in the classroom.

\section{Keywords}

Adventist education. Denominational education. Student profile.

\section{Introdução}

Os relatos do surgimento do ensino confessional no Brasil conduzem, coincidentemente, à história da própria escolarização no país, quando os primeiros missionários católicos vindos da Europa fundaram, na Bahia, a primeira instituição de ensino. ${ }^{1}$ De modo didático, a supremacia da educação católica teve fases que podem ser divididas em três períodos: o primeiro, logo após o descobrimento do Brasil (1500), quando este se tornou colônia de Portugal; o segundo período é marcado pela expulsão dos Jesuítas, que ocorre no ano de 1759, por ordem de Marquês de Pombal; e o terceiro período acontece a partir do ano de 1806, com a chegada da família real de Portugal ao Brasil e subsequente a vinda de imigrantes protestantes.

Já os protestantes fundaram colégios apoiados nos ideais democrático e liberal da elite urbana e por conta da forte influência do capital norte-americano no processo de industrialização, os ideais republicanos de progresso, a necessidade de uma ampla rede de ensino que formasse o cidadão republicano e o tornasse apto para o voto, dentre outros fatores, com o propósito de disseminar os ideais religiosos. ${ }^{2}$ Vale ressaltar que apesar de existir grupos educacionais de distintos segmentos religiosos como judeus, islâmicos, budistas entre outros, esses são minoritários comparados aos católicos e protestantes, não exercendo uma influência significativa na história da educação confessional do país.

Segundo Mendonça, ${ }^{3}$ Marcondes e Seehaber, ${ }^{4}$ no Brasil ocorreram três períodos da inserção do protestantismo: o protestantismo de invasão com tentativas não prósperas ocorridas enquanto o Brasil ainda era colônia de Portugal com duas principais iniciativas de implantação, o primeiro com os huguenotes na Guanabara (1557-1558), e depois com os holandeses no Nordeste (1630-1654). O protestantismo de imigração surge com famílias e grupos vindos da Europa, Estados Unidos e Inglaterra com o intuito de reconstruir suas vidas e fixar residência no novo país. A preocupação desses imigrantes era a preservação da cultura e da fé, e a escola seria fundamental para isto. O protestantismo missionário que

1 SHIGUNOV NETO, Alexandre; MACIEL, Lizete Shizue Bomura. O ensino jesuítico no período colonial brasileiro: algumas discussões. Educar, Curitiba, n. 31, p. 169-189, 2008. Disponível em <http://www.scielo.br/pdf/er/n31/n31a11.pdf>. Acesso em: 29 ago. 2016. p. 175.

2 MENDONÇA, Antônio Gouvêa. O celeste porvir: a inserção do protestantismo no Brasil. São Paulo: ASTE, 2008; RIBEIRO, Viviane; INÁCIO FILHO, Geraldo. Escola pública x escola confessional: as escolas presbiterianas rurais na região do alto Paranaíba, MG. Cadernos de História da Educação, Uberlândia, MG, n. 3, p. 167-176, jan./dez. 2004.

3 MENDONÇA, 2008.

4 MARCONDES, Lea Rocha Lima e; SEEHABER, Liliana C. A identidade do ensino religioso, do rito cristão na história da educação brasileira. Revista Educação em Movimento, Curitiba, v. 3, n. 9, p. 17-28, set./dez. 2004. 
tinha o mesmo objetivo do catolicismo: a evangelização dos brasileiros. A dinâmica do protestantismo missionário se constitui na preocupação de evangelizar aqueles que não pertencem à sua denominação e fé; isso fez com que diversas denominações do protestantismo histórico se fixassem aqui no Brasil: os presbiterianos em 1868, 5 os metodistas em 1870,6 os batistas em $1881^{7}$ e os adventistas do sétimo dia em 1893,8 estabelecidas em São Paulo, Rio de Janeiro, Espírito Santo, Pará, Bahia, Rio Grande do Sul, Paraná, entre outros. ${ }^{9}$

Marcondes e Seehaber também abordam a inserção do protestantismo no Brasil e o vínculo com a escolaridade confessional, lembrando que:

Os primeiros imigrantes [...] criam as primeiras escolas evangélicas para propiciar alfabetização geral, no intuito de que seus filhos pudessem exercer adequadamente a fé e tivessem acesso às Escrituras. De acordo com a sua cultura, o analfabetismo era empecilho ao aprendizado da sua doutrina. Também neste período, missionários norte-americanos, instalaram-se no Oeste paulista fundando escolas para os filhos dos imigrantes protestantes. Outras denominações evangélicas (metodista, presbiteriana, batista), também chegaram ao Brasil neste período, instalando-se em outros Estados com intuito de desenvolver a evangelização criando igrejas e escolas para atender as necessidades locais. ${ }^{10}$

Assim, a partir de meados do século XIX, se notará não apenas a presença dos missionários norte-americanos no Brasil, mas, principalmente, a chegada de missionários educadores e, consequentemente, o estabelecimento de centros educacionais. A introdução da educação protestante na sociedade brasileira se deu, concomitantemente, à pregação dos primeiros missionários, associada com a organização das primeiras igrejas que

5 NASCIMENTO, Ester Fraga Vilas-Bôas Carvalho do. Educar, curar, salvar: uma ilha de civilização no Brasil tropical. Maceió: Ufal, 2007; CLARK, Jorge Úílson. Presbiterianismo do sul em Campinas: primórdio da educação liberal. Tese (Doutorado em Educação) - Programa de Pós-Graduação em Educação, Universidade Estadual de Campinas, Campinas, 2009.

6 MESQUIDA, Peri. Hegemonia norte-americana e educação protestante no Brasil: um estudo de caso. Juiz de Fora: UFJF; São Bernardo do Campo: Editeo, 1994.

7 SILVA, Cleni da. Educação batista: análise histórica de sua implantação no Brasil e de seus desafios no contexto atual. Rio de Janeiro: Juerp, 2004; MACHADO, José Nemésio. Educação batista no Brasil: uma análise complexa. São Paulo: Colégio Batista Brasileiro/Cortez, 1999.

8 GONÇALVES, Sergio. Desafios de uma instituição confessional: Centro Universitário Adventista - UNASP. Dissertação (Mestrado em Educação) - Programa de Pós-Graduação em Educação, Universidade Metodista de Piracicaba, Piracicaba, 2009.

9 ALMEIDA, Jane Soares de. O movimento missionário e educacional protestante na segunda metade do século XIX: para cada igreja uma escola. Educar em Revista, Curitiba, n. 20, p. 185-207, 2002. Disponível em: <https://goo.gl/zxLG7W>. Acesso em: 05 set. 2016.

10 MARCONDES; SEEHABER, 2004, p. 18. 
implantavam escolas paroquiais. Isso sem contar que, "antes de surgirem os salões de culto, já funcionavam as escolas nas casas particulares". ${ }^{11}$

De igual modo, a Igreja Adventista do Sétimo Dia (IASD) fez um esforço pelo estabelecimento de escolas paroquiais que atendessem às suas crianças. As comunidades locais compostas de membros leigos preocupavam-se em oferecer a seus filhos uma educação sob o prisma da filosofia adventista. Juntamente a isso, um dos motivos citados por Sellaro para a criação de tais escolas paroquiais foi a discriminação e intolerância religiosa contra os alunos de origem protestante junto às escolas públicas. ${ }^{12}$ Foi justamente por esse mesmo motivo que os pioneiros adventistas empreenderam o estabelecimento de escolas. ${ }^{13}$ Este seria um modo de evitar o contato das crianças com uma educação laica, o que daria margem a possíveis desvios e também uma maneira de nutrir os princípios religiosos desde cedo introduzidos no contexto das crianças.

A partir disso, surgiram dois tipos de escolas ligadas aos adventistas: as paroquiais, que tinham o objetivo de fortalecer a membresia; e os internatos, ligados mais fortemente à preparação da liderança eclesiástica. Sobre as escolas paroquiais, Schünemann relata que:

[...] eram basicamente multisseriadas e utilizavam o espaço das igrejas já existentes. [...] surgiram para atender a necessidade interna de manter as suas crianças livres do que era entendido como ameaças à formação adventista: ideias liberais da Teologia, o ensino do Darwinismo e o convívio com pessoas sem formação religiosa. ${ }^{14}$

A característica básica dessas escolas era ensinar aos filhos adventistas os princípios doutrinários da igreja. As escolas formadas eram pequenas, quase sempre tinham apenas um professor que era sempre adventista. Dessa forma, a educação fundamental se tornou parte integrante da estrutura adventista, tanto quanto a educação superior que, posteriormente, foi instituída em sistemas de internato.

Apesar da forte influência dos internatos na rede escolar adventista, no Brasil essa rede se tornou significativa justamente por causa das escolas paroquiais espalhadas em diversas localidades e não necessariamente por causa dos internatos. Com o crescimento e

11 SOUZA, José Roberto de; DIAS, Júlio César Tavares. A educação protestante no brasil: o caso do Colégio Agnes. Revista de teologia e ciências da religião, v. 4, n. 1, p. 87-103, dez. 2014. p. 95; SANTOS, Taciana Brasil dos. Formação, transformação, adaptação: origens de uma instituição educativa confessional batista em Belo Horizonte/MG, década de 1920. História da Educação, Santa Maria, v. 19, n. 47, p. 271-288, dez. 2015. Disponível em: <http://goo.gl/hUYeF7>. Acesso em: 05 set. 2016.

12 SELLARO, Lêda Rejane Accioly. Educação e religião: colégios protestantes em Pernambuco na década de 20. Dissertação (Mestrado em Educação) - Programa de Pós-graduação em Educação, Universidade Federal de Pernambuco, Recife, 1987.

13 SCHÜNEMANN, Haller Elinar Stach. A Educação confessional fundamentalista no Brasil atual: uma análise do sistema escolar da IASD. Revista de Estudos da Religião. Campinas, p. 71-97, set. 2009. Disponível em: <http:/ /goo.gl/OZ4mcg>. Acesso em: 03 maio 2014.

14 SCHÜNEMANN, 2009, p. 76. 
expansão da igreja, naturalmente ocorria o mesmo em relação à área educacional. Os pioneiros adventistas no Brasil foram impulsionados pelo conselho de sua pioneira Ellen G. White de que "em todas as nossas igrejas deveria haver escolas"15 e procuravam aumentar a quantidade de escolas para equiparar ao número de igrejas estabelecidas. Dessa forma, no ano de 1906, 42\% das igrejas possuíam escolas. ${ }^{16}$

As escolas paroquiais adventistas ganharam visibilidade na sociedade somente nas duas últimas décadas do século XX. Apesar dos registros escassos, Azevedo afirma que, em 1899, a Associação Geral da IASD registra a existência de quatro escolas no Brasil. ${ }^{17}$ Já em 1906 havia 10 escolas para 24 igrejas. Posteriormente, chegou a haver mais escolas do que igrejas em algumas regiões. Conforme França, a Rede Adventista de Educação ostenta uma organização burocraticamente forte e elevadamente centralizada, tornando-se um dos maiores sistemas confessionais do mundo. ${ }^{18}$ São 7.883 instituições distribuídas em 115 países, da Educação Infantil ao Ensino Superior, com aproximadamente 90 mil educadores e com quase 1,8 milhões de alunos. Atualmente no Brasil, a rede conta com 568 unidades escolares, 10 mil professores e cerca de 176 mil alunos. Além dessas unidades, a organização mantém 15 colégios em regime de internato, sendo que sete deles oferecem desde a Educação Infantil à Pós-Graduação. ${ }^{19}$

A Rede Educacional Adventista possui princípios específicos, tendo a Bíblia como base do seu fundamento filosófico, e que a partir da missão estabelecida pela IASD, denota como objetivo educacional preparar seus alunos para a vida útil, estimulando a religiosidade, harmonizando o desenvolvimento integral das faculdades física, metal e espiritual, a partir dos valores bíblicos, contrapondo-se a ideias que desviam os alunos do propósito restaurador da educação proposta por sua filosofia, reagindo contra ao que considera cultura secular. Declaram respeitar todas as crenças populares e propostas governamentais, no entanto, seguem princípios e doutrinas próprias, que muitas vezes entram em conflito com esta cultura. ${ }^{20}$

15 WHITE, Ellen G. Conselhos a professores, pais e estudantes. Tatuí: Casa Publicadora Brasileira, 2000. p. 150.

16 AZEVEDO, R. C. O ensino adventista de nível fundamental no Brasil. In: TIMM, Albert. R. (Org.). A educação adventista no Brasil: uma história de aventuras e milagres. Engenheiro Coelho: UNASPRES, 2004. p. 33; CARVALHO, Francisco Luiz Gomes de. O ensino religioso no ensino superior da educação adventista: presença e impasses. Dissertação (Mestrado em Ciências das Religiões) - Pontifícia Universidade Católica de São Paulo, São Paulo, 2012.

17 AZEVEDO, 2004.

18 FRANÇA, Giseli Zilli Pércio. Educação física escolar: reflexões e ações a partir da filosofia educacional adventista. Dissertação (Mestrado em Ciências do Movimento Humano) - Universidade Metodista de Piracicaba, Piracicaba, 2015.

19 SUTHERLAND, E. A. Estudos em educação cristã. Centro de Pesquisas Ellen G. White: Centro White Press, 2013.

20 SUTHERLAND, 2013. 
Como característica inicial, os alunos da Rede Adventista eram quase sempre filhos de adventistas, principalmente nos internatos, ${ }^{21}$ suprindo uma necessidade interna da igreja, já que o ensino público era considerado inadequado. Obedeciam a sua pioneira Ellen G. White, recomendando que a igreja precisa ter "uma obra especial a fazer no educar e preparar suas crianças a fim de que, frequentando outras escolas ou em outros convívios, não venham a ser influenciadas pelos que têm hábitos corruptos". ${ }^{22}$

Apesar desse viés tradicional e "fundamentalista",23 as escolas da Rede Adventista têm tido grande demanda por matrículas, procurados por famílias que esperam uma educação mais rígida e fundamentada em princípios cristãos. ${ }^{24}$ Assim, com o crescimento da Rede Educacional Adventista, um número cada vez mais crescente de alunos nãoconfessionais passou a estudar na rede. Em 1945, a proporção de estudantes em escolas adventistas para o número de membros da igreja era de 25 para cada 100. Essa proporção se manteve quase constante até 1965. Desde então, a proporção tem caído consideravelmente até 15 para cada 100 em 1985, e 9 para cada 100 no ano 2000. Ao mesmo tempo, mais alunos não-confessionais continuaram a se matricular, o que fez baixar a proporção de estudantes adventistas para perto de 5 para cada 100 membros. $^{25}$

Segundo Meira Júnior, desde que as escolas adventistas aceitaram alunos nãoconfessionais, as instituições passaram a ter que lidar com a tensão entre abandonar as características religiosas e tomar posição no cenário acadêmico. ${ }^{26}$ De qualquer forma, o atual perfil discente certamente tem trazido novos desafios para a Rede. Por isso, o estudo do perfil se torna relevante porque possibilita compreender quem são esses sujeitos, permite discutir sua identidade e fornece informações importantes que poderão delinear novas ações para esse segmento educacional.

\section{Metodologia}

O desenho metodológico do presente estudo é do tipo descritivo-exploratório, sendo realizado com uso de questionários aplicados a alunos do ensino básico (Fundamental e Médio) de seis escolas confessionais pertencentes à Rede Adventista de Educação localizadas na Zona Leste e Norte da cidade de São Paulo.

21 KLEIN, Débora. Pedagogia na colina: a Faculdade Adventista de Educação da Universidade Adventista de São Paulo de 1971 a 1999. Dissertação (Mestrado em Educação) - Programa de Pós-Graduação em Educação, Universidade Nove de Julho - UNINOVE, São Paulo, 2008.

22 WHITE, Ellen G. Orientação da criança. Tatuí: Casa Publicadora Brasileira, 2007. p. 312.

23 SCHÜNEMANN, 2009, p. 75.

24 BARROSO, Geraldo et al. Ensino Adventista: diferencial pedagógico. Revista de TCC, Recife, v. 2, 2007. Disponível em: <http://goo.gl/XrdYVD>. Acesso em: 05 set. 2016.

25 KNIGHT, George R. Por que educação adventista? Revista de Educação Adventista. 2006. Disponível em: <http://goo.gl/oFVnPw>. Acesso em: 5 set. 2016.

26 MEIRA JÚNIOR, Isaac Malheiros. A importância do ensino religioso na pedagogia adventista. Monografia (Pós-Graduação Lato Sensu em Educação Religiosa Escolar e Teologia Comparada) - Escola Superior Aberta do Brasil - ESAB, Vila Velha, 2010. 
Trata-se de um estudo quantitativo, de caráter exploratório e descritivo. Os estudos exploratórios e descritivos pretendem buscar informações apuradas no tocante a grupos, instituições, sujeitos ou circunstâncias, caracterizando-os e evidenciando um perfil, conduzido dentro do contexto de um conhecimento prévio a partir do ponto inicial de um estudo (colocação da questão) para o ponto final (obtenção de uma resposta). ${ }^{27}$

A amostra foi composta por 1.787 (100\%) estudantes do sexto ano do Ensino Fundamental ao terceiro ano do Ensino Médio, em seis escolas, sendo 114 (6,3\%) oriundos da Escola A, 350 (19,5\%) da Escola B, 529 (29,6\%) da Escola C, 315 (17,6\%) da Escola D, 132 $(7,3 \%)$ da Escola E e $347(19,4 \%)$ da Escola F.

Segundo a Associação Paulista Leste da IASD, ${ }^{28}$ a análise do perfil foi realizada com base num questionário semiestruturado elaborado por Abdala e outros, ${ }^{29}$ que fora aplicado em estudantes de Instituto de Ensino Superior. ${ }^{30}$ Segundo a Mantenedora, a intenção do levantamento de dados foi obter informações referentes à espiritualidade/religiosidade da instituição e dos alunos para serem utilizadas no desenvolvimento do Plano Mestre de Desenvolvimento Espiritual (PMDE), projeto que "prepara temas importantes para serem apresentados aos alunos de todas as faixas etárias com a finalidade de desenvolver neles a religiosidade/espiritualidade", além da tentativa de se adquirir opinião quanto aos serviços prestados pela instituição. ${ }^{31}$

Conforme a Associação Paulista Leste da IASD, a coleta de dados ocorreu em sala de aula, mediante agendamento prévio pela coordenação das escolas, para que não interferisse nas atividades acadêmicas. ${ }^{32}$ Os estudantes que aceitaram participar do estudo receberam orientações quanto ao objetivo da pesquisa e garantia do anonimato. A participação dos estudantes foi voluntária com total liberdade de recusarem a colaborar com a investigação.

As informações foram coletadas mediante instrumento on-line no programa Survey Monkey e a análise dos dados foi feita através do programa estatístico Statistical Package of Social Science (SPSS). A investigação foi realizada, no ano de 2012, entretanto fora divulgada recentemente por meio eletrônico e seu banco de dados disponibilizado pela Mantenedora ao autor desta pesquisa.

27 RAMPAZZO, Lino. Metodologia científica: para alunos dos cursos de graduação e pós-graduação. São Paulo: Loyola, 2005.

28 Mentenedora regional das escolas da Rede Adventista de Educação responsável pelas seis escolas investigadas.

29 ABDALA, Gina Andrade et al. A religiosidade/espiritualidade como influência positiva na abstinência, redução e/ou abandono do uso de drogas. Revista Formadores, v. 2, n. 3, p. 447, jan. 2009.

30 ASSOCIAÇÃO PAULISTA LESTE DA IASD. Pesquisa de satisfação: alunos. Disponível em: <http://apl.adventistas.org/_pesquisa-educacao-apl/>. Acesso em: 01 ago. 2016.

31 EDUCAÇÃO ADVENTISTA. Plano mestre de desenvolvimento espiritual. Disponível em: $<$ www.pmde.com.br>. Acesso em: 10 set. 2016.

32 ASSOCIAÇÃO PAULISTA LESTE DA IASD, 2016. 


\section{Resultados e discussão}

Dos 1.787 alunos inquiridos, 1,5\% estão com menos de 11 anos; 64,4\% estão entre 11 e 14 anos; 31,9\% estão com idade entre 15 e 17 anos; e 1,9\% com 18 anos ou mais; e 0,3\% não responderam ao questionamento. Quanto ao gênero, 47,5\% são do sexo masculino e $52,2 \%$ são do sexo feminino, tendo $0,4 \%$ não respondentes. Adotando-se o padrão do IBGE (1996), a autoclassicação da cor da pele se divide em cinco tipos: branca, preta, amarela, parda e indígena. Nessa pesquisa, as cores de pele referidas predominantes foram a branca (56\%), a parda $(30,6 \%)$ e 6,9\% se declararam de cor preta (Tabela 1$)$.

Do total de alunos investigados, 309 estão no sexto ano do Ensino Fundamental, o que equivale a 17,3\%; 299 (16,7\%) estão no sétimo ano; 305 (17,1\%) alunos estão no oitavo ano; 307 (17,2\%) frequentam o nono ano. Referente ao Ensino Médio 205 alunos estão no $1^{\circ}$ ano, equivalente a 11,5\%; $200(11,1 \%)$ estão no $2^{\circ}$ ano; 155 (8,7\%) estão no $3^{\circ}$ ano; e 7 alunos não responderam, equivalente a $0,4 \%$. Assim $68,3 \%$ estão frequentando o Ensino Fundamental e 31,3\% o Ensino Médio (Tabela 1).

Tabela 1: Caracterização dos alunos das Escolas Adventistas, participantes da pesquisa, quanto a idade, sexo, cor e escolaridade.

\begin{tabular}{|c|c|c|c|}
\hline Variável & Categoria & & $\%$ \\
\hline \multirow[t]{5}{*}{ Idade } & Menos de 11 & 26 & 1,5 \\
\hline & 11 a 14 & 1.150 & 64,4 \\
\hline & 15 a 17 & 571 & 31,9 \\
\hline & 18 ou mais & 35 & 1,9 \\
\hline & Não respondida & 5 & 0,3 \\
\hline \multirow[t]{3}{*}{ Sexo } & Masculino & 848 & 47,5 \\
\hline & Feminino & 932 & 52,2 \\
\hline & Não respondida & 7 & 0,4 \\
\hline \multirow[t]{6}{*}{ Cor } & Branca & 1001 & 56,0 \\
\hline & Preta & 124 & 6,9 \\
\hline & Parda & 547 & 30,6 \\
\hline & Amarela & 59 & 3,3 \\
\hline & Indígena & 47 & 2,6 \\
\hline & Não respondida & 9 & 0,5 \\
\hline \multirow[t]{8}{*}{ Escolaridade } & $6^{\circ}$ & 309 & 17,3 \\
\hline & $7^{\circ}$ & 299 & 16,7 \\
\hline & $8^{\circ}$ & 305 & 17,1 \\
\hline & $9^{\circ}$ & 307 & 17,2 \\
\hline & $1^{\circ} \mathrm{EM}$ & 205 & 11,5 \\
\hline & $2^{\circ} \mathrm{EM}$ & 200 & 11,2 \\
\hline & $3^{\circ} \mathrm{EM}$ & 155 & 8,7 \\
\hline & Não respondida & 7 & 0,4 \\
\hline
\end{tabular}

Fonte: Elaborado pelo autor. 
Também foi indagado aos alunos quanto a "com quem eles moravam". Dos 1787 alunos, 60\% declararam morar com os pais, os demais moram somente com o pai ou mãe e suas respectivas famílias ou outras opções. Para Sanchez, Oliveira e Nappo, o viver com uma família estruturada é identificado como sendo o fator protetor mais importante para prevenção contra uso de drogas ou influências negativas, pois fornece elementos essenciais como apoio, carinho e proteção. ${ }^{33}$ A família apresenta-se, como base fundamental da educação na infância e adolescência e como parâmetro de controle das atitudes e companhias dos filhos

Tabela 2: Distribuição dos alunos conforme a pergunta "com quem você mora?".

\begin{tabular}{llcc}
\hline Variável & \multicolumn{1}{c}{ Categoria } & $\mathbf{N}$ & $\mathbf{\%}$ \\
\hline Com quem moram & Mora somente com o pai & 39 & $2,2 \%$ \\
& Mora somente com a mãe & 263 & $14,7 \%$ \\
& Mora um pouco com cada & 64 & $3,6 \%$ \\
& Não mora com os pais & 74 & $4,1 \%$ \\
& Mora com os pais & 1072 & $60,0 \%$ \\
& Mora com mãe e padrasto & 63 & $3,5 \%$ \\
& Mora com pai e madrasta & 17 & $1,0 \%$ \\
& Outro & 183 & $10,2 \%$ \\
& Não respondida & 12 & $0,7 \%$ \\
\hline
\end{tabular}

Fonte: Elaborado pelo autor.

Outros dados que foram levantados referem-se à questão "se os alunos têm uma religião específica". Dos 1787 participantes, 16\% relataram não ter religião, 82\% relataram ter religião, e 1,6\% dos alunos não responderam. Na descrição da religião, 216 estudantes $(12,1 \%)$ declararam não ter religião, 605 (33,9\%) disseram pertencer à Igreja Adventista do Sétimo Dia, 604 (33,8\%) declararam pertencer a igrejas protestantes diversas, 269 (15,1\%) pertencem à Igreja Católica, 40 (2,2\%) professaram ser Espíritas, 25 (1,4\%) pertencem a outras denominação e 28 alunos (1,6\%) não responderam. Esses dados podem ser melhor visualizados na Figura 1.

33 SANCHEZ, Zila Van der Meer; OLIVEIRA, Lúcio Garcia de; NAPPO, Solange Aparecida. Fatores protetores de adolescentes contra o uso de drogas com ênfase na religiosidade. Ciência E Saúde Coletiva (online), Rio de Janeiro, v. 9, n. 1, p. 43-55, 2004. Disponível em: <https://goo.gl/sQK1qs>. Acesso em 20 set. 2016. 
Figura 1: Percentual de alunos por religião professada.

Qual a sua religião?
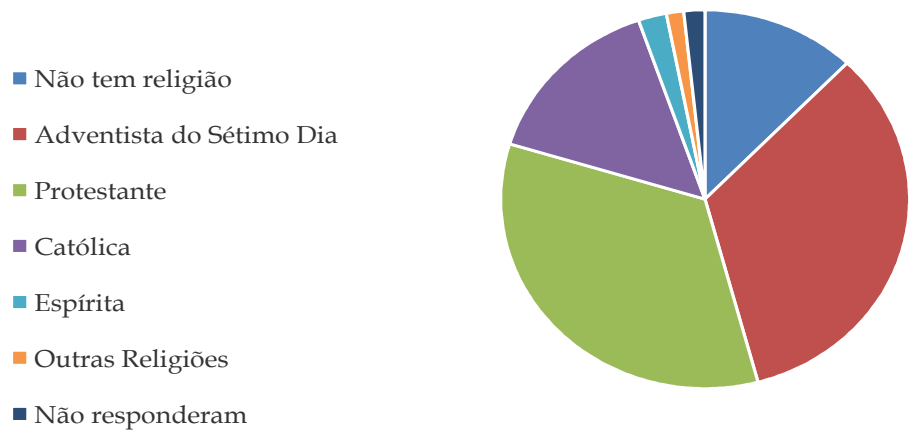

Fonte: Elaborado pelo autor.

Questionando-se sobre a relação das crenças e o desempenho acadêmico, identificou-se que, para os alunos das Escolas Adventistas participantes da pesquisa, $39,4 \%$ acreditam que existe alguma influência da religião no bom desempenho de suas atividades acadêmicas, 34,2\% afirmaram que a relação é de muita influência, 15,2\% disseram influenciar pouco, 9,5\% responderam que as crenças não influenciam no desempenho acadêmico, e 1,6\% não responderam. Quanto à questão se suas crenças afetam suas práticas de saúde (viver saudável), 15,3\% (n= 273 alunos) relataram não ter nenhuma influência, 12,1\% ( $\mathrm{n}=217)$ pouca influência, 31,8\% ( $\mathrm{n}=568)$ alguma influência, 38,9\% ( $\mathrm{n}=696)$ muita influência e 1,8\% (n=33) não responderam (Tabela 3).

Tabela 3: Impacto da crença religiosa no desempenho acadêmico e nas práticas de saúde.

\begin{tabular}{rlcc}
\hline Variável & \multicolumn{1}{c}{ Categoria } & N & \% \\
\hline Desempenho acadêmico & Nenhuma Influência & 170 & $9,5 \%$ \\
& Pouca Influência & 272 & $15,2 \%$ \\
& Alguma Influência & 704 & $39,4 \%$ \\
& Muita Influência & 612 & $34,2 \%$ \\
& Não respondida & 29 & $1,6 \%$ \\
\hline Saúde (viver saudável) & Nenhuma Influência & 273 & $15,3 \%$ \\
& Pouca Influência & 217 & $12,1 \%$ \\
& Alguma Influência & 568 & $31,8 \%$ \\
& Muita Influência & 696 & $38,9 \%$ \\
\hline & Não respondida & 33 & $1,8 \%$ \\
\hline
\end{tabular}

Fonte: Elaborado pelo autor. 
No quesito seguinte, em que a resposta teria que ser dada como sim ou não, foi perguntado "se a espiritualidade/religiosidade é um auxílio que ajuda a vencer os desafios da vida". Do total de respostas, 1661 alunos (92\%) responderam positivamente. Quanto à questão "qual a importância da aula de religião para sua espiritualidade/religiosidade", 8,4\% responderam que não é importante, 16,1\% pouco importante, 30,8\% como sendo importante, 21,8\% muito importante, 20,3\% como essencial e 2,5\% não responderam (Tabela 4). Segundo Meira Júnior, na rede adventista, as aulas de ensino religioso não são opcionais, mas fazem parte do curso normal dos estudantes em todos os níveis. ${ }^{34} \mathrm{O}$ número semanal de aulas de ensino religioso é variável de lugar para lugar, ainda não há uma padronização na rede.

Tabela 4: Influência da espiritualidade/religiosidade para vencer os desafios da vida e importância das aulas de religião na espiritualidade/religiosidade.

\begin{tabular}{llcc}
\hline \multicolumn{1}{c}{ Variável } & \multicolumn{1}{c}{ Categoria } & $\mathbf{N}$ & $\mathbf{\%}$ \\
Ajuda a vencer os desafios & Sim & 1661 & $92,9 \%$ \\
& Não & 100 & $5,6 \%$ \\
& Não respondida & 26 & $1,5 \%$ \\
\hline \multirow{2}{*}{ Importância da aula de religião } & Não é importante & 151 & $8,4 \%$ \\
& Pouco importante & 288 & $16,1 \%$ \\
& Importante & 551 & $30,8 \%$ \\
& Muito importante & 390 & $21,8 \%$ \\
& Essencial & 363 & $20,3 \%$ \\
& Não respondida & 44 & $2,5 \%$ \\
\hline
\end{tabular}

Fonte: Elaborado pelo autor.

\section{Considerações finais}

À guisa de conclusão, podem-se apontar alguns aspectos relevantes encontrados na coleta de dados, como o percentual de apenas 33,9\% de alunos que professam ter a crença Adventista do Sétimo Dia. Ao mesmo tempo, um grande percentual de alunos consideram a religiosidade/espiritualidade como algo em torno de importante a essencial. Isso demonstraria um perfil de alunado receptivo à influência de uma educação confessional e religiosa.

Após a revisão de literatura, verificou-se que pesquisas sobre instituições de ensino confessionais desenvolvidas no panorama acadêmico ainda são abordadas de forma incipiente, sendo pouco difundidas em âmbito nacional, principalmente relacionadas às repercussões no sistema educacional e na sociedade. Em vista disso, sugere-se o desenvolvimento de pesquisas envolvendo temas relacionados ao ensino confessional e sua influência na vida de crianças e adolescentes.

34 MEIRA JÚNIOR, 2010. 
A continuidade de estudos nessa perspectiva poderá contribuir para o avanço científico e auxiliar não somente os acadêmicos, como os profissionais que atuam nessas instituições, a considerar a educação religiosa como um aspecto integrante no desenvolvimento do ser humano que pode atuar como fator protetivo, capaz de promover a saúde, a resiliência e a qualidade de vida em diferentes contextos sociais.

\section{Referências}

ABDALA, Gina Andrade et al. A religiosidade/espiritualidade como influência positiva na abstinência, redução e/ou abandono do uso de drogas. Revista Formadores, v. 2, n. 3, p. 447, jan. 2009.

ALMEIDA, Jane Soares de. O movimento missionário e educacional protestante na segunda metade do século XIX: para cada igreja uma escola. Educar em Revista, Curitiba, n. 20, p. 185-207, 2002. Disponível em: <https://goo.gl/zxLG7W>. Acesso em: 05 set. 2016.

ASSOCIAÇÃO PAULISTA LESTE DA IASD. Pesquisa de satisfação: alunos. Disponível em: <http://apl.adventistas.org/_pesquisa-educacao-apl/>. Acesso em: 01 ago. 2016.

AZEVEDO, R. C. O ensino adventista de nível fundamental no Brasil. In: TIMM, Albert. R. (Org.). A educação adventista no Brasil: uma história de aventuras e milagres. Engenheiro Coelho: UNASPRES, 2004.

BARROSO, Geraldo et al. Ensino Adventista: diferencial pedagógico. Revista de TCC, Recife, v. 2, 2007. Disponível em: <http://goo.gl/XrdYVD>. Acesso em: 05 set. 2016.

CARVALHO, Francisco Luiz Gomes de. O ensino religioso no ensino superior da educação adventista: presença e impasses. Dissertação (Mestrado em Ciências das Religiões) Pontifícia Universidade Católica de São Paulo, São Paulo, 2012.

CLARK, Jorge Uílson. Presbiterianismo do sul em Campinas: primórdio da educação liberal. Tese (Doutorado em Educação) - Programa de Pós-Graduação em Educação, Universidade Estadual de Campinas, Campinas, 2009.

EDUCAÇÃO ADVENTISTA. Plano mestre de desenvolvimento espiritual. Disponível em: <www.pmde.com.br>. Acesso em: 10 set. 2016.

FRANÇA, Giseli Zilli Pércio. Educação física escolar: reflexões e ações a partir da filosofia educacional adventista. Dissertação (Mestrado em Ciências do Movimento Humano) Universidade Metodista de Piracicaba, Piracicaba, 2015.

GONÇALVES, Sergio. Desafios de uma instituição confessional: Centro Universitário Adventista - UNASP. Dissertação (Mestrado em Educação) - Programa de Pós-Graduação em Educação, Universidade Metodista de Piracicaba, Piracicaba, 2009.

KLEIN, Débora. Pedagogia na colina: a Faculdade Adventista de Educação da Universidade Adventista de São Paulo de 1971 a 1999. Dissertação (Mestrado em Educação) - Programa 
de Pós-Graduação em Educação, Universidade Nove de Julho - UNINOVE, São Paulo, 2008.

KNIGHT, George R. Por que educação adventista? Revista de Educação Adventista. 2006. Disponível em: <http://goo.gl/oFVnPw>. Acesso em: 5 set. 2016.

MACHADO, José Nemésio. Educação batista no Brasil: uma análise complexa. São Paulo: Colégio Batista Brasileiro/Cortez, 1999.

MARCONDES, Lea Rocha Lima e; SEEHABER, Liliana C. A identidade do ensino religioso, do rito cristão na história da educação brasileira. Revista Educação em Movimento, Curitiba, v. 3, n. 9, p. 17-28, set./dez. 2004.

MEIRA JÚNIOR, Isaac Malheiros. A importância do ensino religioso na pedagogia adventista. Monografia (Pós-Graduação Lato Sensu em Educação Religiosa Escolar e Teologia Comparada) - Escola Superior Aberta do Brasil - ESAB, Vila Velha, 2010.

MENDONÇA, Antônio Gouvêa. O celeste porvir: a inserção do protestantismo no Brasil. São Paulo: ASTE, 2008.

MESQUIDA, Peri. Hegemonia norte-americana e educação protestante no Brasil: um estudo de caso. Juiz de Fora: UFJF; São Bernardo do Campo: Editeo, 1994.

NASCIMENTO, Ester Fraga Vilas-Bôas Carvalho do. Educar, curar, salvar: uma ilha de civilização no Brasil tropical. Maceió: Ufal, 2007.

RAMPAZZO, Lino. Metodologia científica: para alunos dos cursos de graduação e pósgraduação. São Paulo: Loyola, 2005.

RIBEIRO, Viviane; INÁCIO FILHO, Geraldo. Escola pública x escola confessional: as escolas presbiterianas rurais na região do alto Paranaíba, MG. Cadernos de História da Educação, Uberlândia, MG, n. 3, p. 167-176, jan./dez. 2004.

SANCHEZ, Zila Van der Meer; OLIVEIRA, Lúcio Garcia de; NAPPO, Solange Aparecida. Fatores protetores de adolescentes contra o uso de drogas com ênfase na religiosidade. Ciência E Saúde Coletiva (online), Rio de Janeiro, v. 9, n. 1, p. 43-55, 2004. Disponível em: <https://goo.gl/sQK1qs>. Acesso em 20 set. 2016.

SANTOS, Taciana Brasil dos. Formação, transformação, adaptação: origens de uma instituição educativa confessional batista em Belo Horizonte/MG, década de 1920. História da Educação, Santa Maria, v. 19, n. 47, p. 271-288, dez. 2015. Disponível em: <http://goo.gl/hUYeF7>. Acesso em: 05 set. 2016.

SCHÜNEMANN, Haller Elinar Stach. A Educação confessional fundamentalista no Brasil atual: uma análise do sistema escolar da IASD. Revista de Estudos da Religião. Campinas, p. 71-97, set. 2009. Disponível em: <http:/ / goo.gl/OZ4mcg>. Acesso em: 03 maio 2014.

SELLARO, Lêda Rejane Accioly. Educação e religião: colégios protestantes em Pernambuco na década de 20. Dissertação (Mestrado em Educação) - Programa de Pós-graduação em Educação, Universidade Federal de Pernambuco, Recife, 1987. 
SHIGUNOV NETO, Alexandre; MACIEL, Lizete Shizue Bomura. O ensino jesuítico no período colonial brasileiro: algumas discussões. Educar, Curitiba, n. 31, p. 169-189, 2008. Disponível em <http://www.scielo.br/pdf/er/n31/n31a11.pdf>. Acesso em: 29 ago. 2016.

SILVA, Cleni da. Educação batista: análise histórica de sua implantação no Brasil e de seus desafios no contexto atual. Rio de Janeiro: Juerp, 2004.

SOUZA, José Roberto de; DIAS, Júlio César Tavares. A educação protestante no brasil: o caso do Colégio Agnes. Revista de teologia e ciências da religião, v. 4, n. 1, p. 87-103, dez. 2014.

SUTHERLAND, E. A. Estudos em educação cristã. Centro de Pesquisas Ellen G. White: Centro White Press, 2013.

WHITE, Ellen G. Conselhos a professores, pais e estudantes. Tatuí: Casa Publicadora Brasileira, 2000.

. Orientação da criança. Tatuí: Casa Publicadora Brasileira, 2007. 